
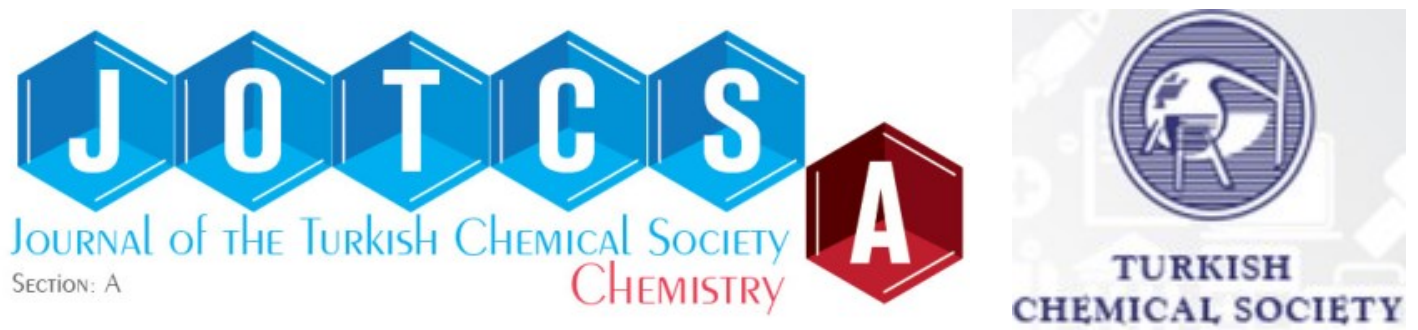

\title{
A Green and Efficient Process for the Synthesis of Benzothiazinones using Phosphate Fertilizers MAP, DAP and TSP as Heterogeneous Catalysts
}

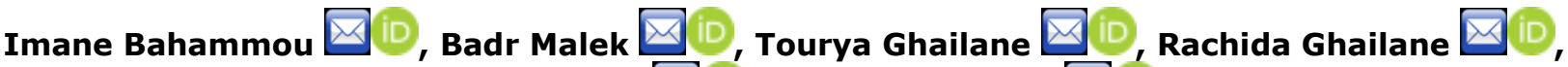 \\ Said Boukhris $\triangle$, Abdelaziz Souizi*
}

Laboratory of Organic, Organometallic and Theoretical Chemistry, University Ibn Tofail, B.P.

Abstract: The aim of this work is to demonstrate the efficiency of the phosphate fertilizers monoammonium phosphate (MAP), di-ammonium phosphate (DAP), and triple-super phosphate (TSP) as a "green" heterogeneous catalyst for the synthesis of 2-aryl-2H-benzo[b][1,4]thiazin-3(4H)-ones via the C$\mathrm{S}$ and $\mathrm{C}-\mathrm{N}$ coupling process of gem-dicyano epoxide with a-aminothiophenol. To optimize the reaction conditions, the synthesis was conducted with a range of solvents, catalyst amounts, and particle sizes of the catalyst. Also, the recyclability potential of the catalysts was confirmed by using the recycled catalyst.

Keywords: Heterogeneous catalyst, phosphate fertilizer, MAP, DAP, TSP, Benzothiazinone.

Submitted: May 10, 2019. Accepted: August 09, 2019.

Cite this: Bahammou I, Malek B, Ghailane T, Ghailane R, Boukhris S, Souizi A. A Green and Efficient Process for the Synthesis of Benzothiazinones using Phosphate Fertilizers MAP, DAP and TSP as Heterogeneous Catalysts. JOTCSA. 2019;6(3):349-54.

DOI: https://doi.org/10.18596/jotcsa.563093.

*Corresponding author. E-mail: Souizi@yahoo.com. Tel: +212661183260.

\section{INTRODUCTION}

To date, benzothiazinone (BTZ) skeleton have been extensively used as pharmacophore group for the construction of numerous biologically active compounds such as anti-tubercular (1), antimicrobial (2), allosteric modulator (3), inhibitor of glycogen synthase kinase $3 \beta$ (3), monoamine oxidase $B$ inhibitors (4), adenosine A2A receptor antagonists (4), antioxidant (5), anti-candida (6) and antitumor agents (7).

Currently, BTZ compounds were identified as a possible new class of acetylcholinesterase inhibitors for curing the symptoms of Alzheimer's disease (8).

In continuation of evaluation of BTZ's properties, Ghailane et al. (9) were able to classify some BTZ derivatives as anticorrosive agents for mild steel in $1 \mathrm{M} \mathrm{HCl}$ based on quantum chemical studies and electrochemical measurements.
Given the importance of BTZ heterocyclic systems, they have been the object of several synthetic studies. For example, BTZ derivatives were successfully synthesized by the condensation of a-aminothiophenol with aryltrichlorocarbinol (10), or dibromonitroacrylates (11), from methyl 2iodobenzoate and cyclic thiourea (12) or 2mercaptoacetate and substituted 2-iodoanilines (13) via the Cu-catalyzed coupling processes. In attempts to establish a green approach to elaborate new derivatives of BTZ, Sharifi et al. (14) developed a green synthesis of various benzothiazinones via the condensation of 2bromoalkanoates with a-aminothiophenol using ball milling and $\mathrm{KF}-\mathrm{Al}_{2} \mathrm{O}_{3}$ support. Recently, new, facile, and regio-controlled methods to obtain BTZ derivatives by reacting a-aminothiophenol with different electron acceptor epoxides were reported (15). Therefore, the improvement of these methods in terms of reaction time, product purity and yield is highly desirable given environmental considerations. 
MAP, DAP, and TSP are ones of the most important and popular members of phosphate fertilizers family due to their composition rich in nitrogen (from $\mathrm{NH}_{4}{ }^{+}$(MAP, DAP)), phosphorus (from $\mathrm{PO}_{4}{ }^{3-}$ (MAP, DAP, TSP)) and calcium (from $\mathrm{Ca}(\mathrm{TSP}))$. Nowadays, they prove to be ecofriendly, economically and highly active heterogeneous catalysts for Knoevenagel condensation (16), 2,3-dihydroquinazolin-4(1H)one synthesis (17) and synthesis of 1(benzothiazolylamino) methyl-2-naphthol derivatives (18).

As part of our previous efforts to valorize phosphate fertilizers (16) we describe herein a 'green' optimization of the one-pot synthesis of BTZ derivatives from gem-dicyano epoxide $\mathbf{1}$ as described by Ghailane et al. (15) using MAP, DAP and TSP fertilizers as novel heterogeneous and reusable catalysts.

\section{EXPERIMENTAL}

\section{Chemicals and instruments}

Chemicals were purchased from Fluka or Aldrich Companies. Catalysts MAP, DAP and TSP, were purchased from OCP group. They are marked as mention in our previous work (16). MonoAmmonium Phosphate: MAP 11-52-00 - Binary Fertilizer, complex granule with Nitrogen: $11 \% \mathrm{~N}$ and Phosphorus: $52 \% \quad \mathrm{P}_{2} \mathrm{O}_{5}$. Di-Ammonium Phosphate: DAP 18-46-00 - Binary Fertilizer, complex granule with Nitrogen: $18 \% \mathrm{~N}$ and Phosphorus: $46 \% \mathrm{P}_{2} \mathrm{O}_{5}$.Triple Super Phosphate: TSP 00-46-00 - Simple granule Fertilizer with Phosphorus: $46 \% \mathrm{P}_{2} \mathrm{O}_{5}$.

All known compounds were identified by comparing their melting points with literature data. Melting points were recorded on a Wagner \& Munz HEIZBANK Kofler bench.

\section{Separation of catalyst's particles according to their size}

The catalyst was crushed and sieved on a mechanical sieve shaker to provide different size of catalyst particles. Three different powders of catalysts MAP, DAP and TSP were tested in this

work. The first (designated $F_{1}$ ) comprised catalyst powder in size range of 36-71 $\mu \mathrm{m}$. The second (designated $\mathrm{F}_{2}$ ) was of the size range between 71 and $90 \mu \mathrm{m}$. The last powder tested (designated $\mathrm{F}_{3}$ ) comprised between 91 and $120 \mu \mathrm{m}$.

General experimental procedure for the phosphate fertilizers MAP, DAP and TSP catalyzed the one-pot synthesis of $2-(p-$ tolyl)-2H-benzo[b][1,4]thiazin-3(4H)-one, $3 a$

Into a $25 \mathrm{~mL}$ round-bottomed flask equipped with a reflux condenser and mechanical stirrer were placed 2 mmoles of epoxide $\mathbf{1}, 2$ mmoles of aaminothiophenol 2 dissolved in $3 \mathrm{~mL}$ of acetonitrile. $10 \mathrm{~mol} \%$ of catalyst was then added to the mixture. The latter was stirred for an appropriate time. The progress of the reaction was monitored by TLC, eluted with chloroform/petroleum ether (2:1). After completion of the reaction, the mixture was filtered to separate the catalyst. Then, the solvent of the filtrate was removed under vacuum, and the oily residue obtained was triturated with a mixture of diethyl ether and petroleum ether (9:1) to give 2-arylbenzothiazin-3-one as a solid which was collected and crystallized from ethanol.

\section{Recyclability studies on the catalysts}

The catalyst separated from the mixture was rinsed with EtOH $(2 \times 5 \mathrm{~mL})$, dried at $70^{\circ} \mathrm{C}$ for 6 hours and reused for subsequent catalytic reactions.

\section{RESULTS AND DISCUSSION}

\section{Catalytic synthesis of BTZ}

To obtain the optimal reaction conditions, one-pot synthesis of BTZ was carried out using MAP, DAP and TSP as heterogeneous catalysts. The reaction of epoxide $\mathbf{1 a}$ with a-aminothiophenol was selected as a model reaction to produce $2-(p-$ tolyl)- $2 H$-benzo $[b][1,4]$ thiazin-3(4H)-one (3a). In the preliminary studies, the reaction was conducted following the conventional synthesis conditions earlier described (12) in the presence of $10 \mathrm{~mol} \%$ of catalyst from fraction $1\left(F_{1}\right)$ (Scheme 1).<smiles>Cc1ccc(C2OC2C#N)cc1</smiles>

1a<smiles>Nc1ccccc1S</smiles>

2<smiles>Cc1ccc(C2Sc3ccccc3NC2=O)cc1</smiles>

3a

Scheme 1: Synthesis of compounds $\mathbf{3 a}$ in the presence of MAP, DAP or TSP catalysts.

Table 1: Catalytic test runs.

\begin{tabular}{llll}
\hline Entry & Catalyst & Time & Yield (\%) \\
\hline 1 & Neat & $22 \mathrm{~h}$ & 80 \\
2 & MAP & $1 \mathrm{~h} 20$ & 87 \\
3 & DAP & $1 \mathrm{~h}$ & 85 \\
4 & TSP & $2 \mathrm{~h}$ & 82 \\
\hline
\end{tabular}




\section{Influence of reaction parameters}

Effects of reaction solvent

After screening the potential activity of phosphate fertilizers MAP, DAP, and TSP, an optimized procedure for the preparation of $2-(p$-tolyl $)-2 \mathrm{H}$ benzo $[b] 1,4]$ thiazin-3(4H)-one (3a) over these heterogeneous catalysts were therefore developed. Initially, the reaction was carried out in several solvents including $\mathrm{MeCN}$, EtOH, AcOEt, $\mathrm{CHCl}_{3}$ using $10 \mathrm{~mol} \%$ of catalyst $\left(\mathrm{F}_{1}\right)$ (Table 2 ). As shown, the three catalysts tested were highly active and gave the desired BTZ $\mathbf{3 a}$ in high yields within short reaction time in $\mathrm{EtOH}$ (Table 2, entries 4, 5 and 6 ). These results can be explained by the fact that EtOH contains polar molecules and an acidic hydrogen atom which is liable to establish a hydrogen bond with the oxygen atom of epoxide to facilitate the binucleophilic attack of a-aminothiophenol.
Effects of catalysts' amount

The catalytic activities were then tested with a range of catalyst amounts $\left(F_{1}\right)$, from 10 $\mathrm{mol} \%$ up to $40 \mathrm{~mol} \%$, to determine the optimal catalyst loading for each catalyst. The reaction was conducted under otherwise identical reaction conditions in the presence of EtOH as a solvent. As can be seen, MAP, DAP and TSP catalysts exhibited high activities under a catalyst loading of $10 \mathrm{~mol} \%$ and afforded the desired product within 40, 35, and 55 minutes, respectively, in high yields (Table 3, entries 1, 5 and 9). A further increase in the catalysts' amounts up to $40 \mathrm{~mol} \%$ resulted in an extension of the reaction time with a slight decrease in the product yield, indicating the catalyst amount of $10 \mathrm{~mol} \%$ to be optimal. This observation established the excellent catalytic activity of the recently developed catalysts.

Table 2: Optimization of the reaction solvent using MAP, DAP and TSP catalysts.

\begin{tabular}{|c|c|c|c|c|}
\hline Entry & Catalyst (10 mol \%) & Solvent (3 mL) & Time & Yield (\%) \\
\hline 1 & MAP & $\mathrm{MeCN}$ & $1 \mathrm{~h} 20$ & 87 \\
\hline 2 & DAP & $\mathrm{MeCN}$ & $1 \mathrm{~h}$ & 85 \\
\hline 3 & TSP & $\mathrm{MeCN}$ & $2 \mathrm{~h}$ & 82 \\
\hline 4 & MAP & $\mathrm{EtOH}$ & $40 \mathrm{~min}$ & 92 \\
\hline 5 & DAP & $\mathrm{EtOH}$ & $35 \mathrm{~min}$ & 89 \\
\hline 6 & TSP & EtOH & $55 \mathrm{~min}$ & 90 \\
\hline 7 & MAP & AcOEt & 3 h 30 & 75 \\
\hline 8 & DAP & AcOEt & $3 \mathrm{~h}$ & 73 \\
\hline 9 & TSP & AcOEt & $2 \mathrm{~h} 50$ & 65 \\
\hline 10 & MAP & $\mathrm{CHCl}_{3}$ & 3 h 10 & 63 \\
\hline 11 & DAP & $\mathrm{CHCl}_{3}$ & 3 h 40 & 60 \\
\hline 12 & TSP & $\mathrm{CHCl}_{3}$ & $4 \mathrm{~h}$ & 55 \\
\hline
\end{tabular}

Table 3: Optimization of the catalysts amount for the synthesis of 2 -( $p$-tolyl)- $2 H$-benzo $[b][1,4]$ thiazin$3(4 H)$-one $3 a$.

\begin{tabular}{lllll}
\hline Entry & Catalyst & Catalyst loading (\%) & Time & Yield (\%) \\
\hline 1 & MAP & 10 & $40 \mathrm{~min}$ & 92 \\
2 & MAP & 20 & $55 \mathrm{~min}$ & 91 \\
3 & MAP & 30 & $1 \mathrm{~h} 10$ & 85 \\
4 & MAP & 40 & $1 \mathrm{~h} 25$ & 82 \\
5 & DAP & 10 & $35 \mathrm{~min}$ & 89 \\
6 & DAP & 20 & $45 \mathrm{~min}$ & 88 \\
7 & DAP & 30 & $1 \mathrm{~h}$ & 85 \\
8 & DAP & 40 & $1 \mathrm{~h} 15$ & 83 \\
9 & TSP & 10 & $55 \mathrm{~min}$ & 90 \\
10 & TSP & 20 & $1 \mathrm{~h} \mathrm{05}$ & 85 \\
11 & TSP & 30 & $1 \mathrm{~h} \mathrm{20}$ & 83 \\
12 & TSP & 40 & $1 \mathrm{~h} \mathrm{35}$ & 79 \\
\hline
\end{tabular}

\section{Effects of catalysts' particle size}

In the current study, we also focused on determining the effect of the catalysts' particle size in an attempt to compare the results with those obtained in our previous work (18). No remarkable influence of the catalyst particle size on the catalysts activities was observed. The results prove our previous findings that the three phosphate fertilizers MAP, DAP and TSP can constantly show high catalytic activities even when their particle size increases. 
Table 4: Screening of the effects of catalyst particle size on the catalytic activities of MAP, DAP and TSP for the synthesis of $2-(p$-tolyl $)-2 H$-benzo $[b][1,4]$ thiazin-3(4H)-one $\mathbf{3 a}$.

\begin{tabular}{lllll}
\hline Entry & Catalyst $(10 \mathrm{~mol} \%)$ & Particle size range & Time $(\mathrm{min})$ & Yield $(\%)$ \\
\hline 1 & MAP & $36-71 \mu \mathrm{m}$ & 40 & 92 \\
2 & MAP & $71-90 \mu \mathrm{m}$ & 40 & 93 \\
3 & MAP & $90-120 \mu \mathrm{m}$ & 40 & 91 \\
4 & DAP & $36-71 \mu \mathrm{m}$ & 35 & 89 \\
5 & DAP & $71-90 \mu \mathrm{m}$ & 35 & 89 \\
6 & DAP & $90-120 \mu \mathrm{m}$ & 40 & 88 \\
7 & TSP & $36-71 \mu \mathrm{m}$ & 55 & 90 \\
8 & TSP & $71-90 \mu \mathrm{m}$ & 55 & 88 \\
9 & TSP & $90-120 \mu \mathrm{m}$ & 55 & 91 \\
\hline
\end{tabular}

\section{Control of the generality of the catalysts}

To further screen the scope and the generality of our new catalysts, the reaction of aaminothiophenol with various substituted epoxides for the synthesis of BTZ derivatives was studied under the optimized conditions using catalyst from fraction $1\left(F_{1}\right)$. As shown in Table 5, almost all of the epoxide substrates with either electron-withdrawing or electron-donating substitution furnished the corresponding adducts in high yields. It is noteworthy that the reaction time was extended to $45 \mathrm{~min}$ for MAP, 50 min for DAP and $1 \mathrm{~h}$ for TSP when the epoxide was substituted with the nitro group (Table 5, Entries 7, 8 and 9).

Table 5. Synthesis of BTZ derivatives over phosphate fertilizers MAP, DAP and TSP under the optimized

\begin{tabular}{|c|c|c|c|c|c|c|c|}
\hline Entry & $\mathbf{R}$ & 1 & Catalyst & Product & Time (min) & $\mathrm{Mp}\left({ }^{\circ} \mathrm{C}\right)$ & Yield (\%) \\
\hline 1 & $\mathrm{CH}_{3}$ & $1 \mathbf{a}$ & MAP & $3 a$ & 40 & 198-199 & 92 \\
\hline 2 & $\mathrm{CH}_{3}$ & $1 \mathbf{a}$ & DAP & $3 a$ & 35 & 198-199 & 89 \\
\hline 3 & $\mathrm{CH}_{3}$ & $1 a$ & TSP & $3 a$ & 55 & 198-199 & 90 \\
\hline 4 & $\mathrm{Cl}$ & $\mathbf{1 b}$ & MAP & 3b & 25 & $186-187$ & 96 \\
\hline 5 & $\mathrm{Cl}$ & $1 \mathbf{b}$ & DAP & 3b & 30 & $186-187$ & 93 \\
\hline 6 & $\mathrm{Cl}$ & $1 \mathbf{b}$ & TSP & 3b & 40 & $186-187$ & 94 \\
\hline 7 & $\mathrm{NO}_{2}$ & 1c & MAP & 3c & 45 & $202-203$ & 92 \\
\hline 8 & $\mathrm{NO}_{2}$ & 1c & DAP & 3c & 50 & $202-203$ & 85 \\
\hline 9 & $\mathrm{NO}_{2}$ & 1c & TSP & 3c & 60 & $202-203$ & 90 \\
\hline
\end{tabular}

\section{Recyclability studies on the catalysts}

In another study, the reaction of epoxide $\mathbf{1 a}$ and a-aminothiophenol $\mathbf{2}$ was tested in the presence of recovered MAP, DAP and TSP to establish the reusability of the three catalysts developed for the synthesis of 2-(p-tolyl)-2Hbenzo[b][1,4]thiazin-3(4H)-one $\mathbf{3 a}$, the results are displayed in Table 6. To our delight, MAP, DAP and TSP catalysts were found to be reusable with consistency in activity up to four times.

Table 6. Recyclability of MAP, DAP and TSP catalysts.

\begin{tabular}{lllll}
\hline Entry & Catalyst & Run number & Time(min) & Yield (\%) \\
\hline 1 & MAP & 1 & 40 & 92 \\
2 & MAP & 2 & 40 & 92 \\
3 & MAP & 3 & 40 & 91 \\
4 & MAP & 4 & 40 & 90 \\
5 & DAP & 1 & 35 & 89 \\
6 & DAP & 2 & 35 & 88 \\
7 & DAP & 3 & 35 & 88 \\
8 & DAP & 4 & 35 & 87 \\
9 & TSP & 1 & 55 & 90 \\
10 & TSP & 2 & 55 & 88 \\
11 & TSP & 3 & 55 & 88 \\
12 & TSP & 4 & 55 & 87 \\
\hline
\end{tabular}

\section{CONCLUSIONS}

Through this study, we demonstrated the catalytic efficiency of the phosphate fertilizers MAP, DAP and TSP for the C-S and C-N coupling reactions. A "green" optimized procedure was therefore designed for the synthesis of 2-aryl- $2 \mathrm{H}$ - benzo $[b][1,4]$ thiazin-3(4H)-ones from aaminothiophenol and gem-dicyano epoxide.

\section{ACKNOWLEDGEMENT}

This study was financially supported by the Research Excellence Award Program of the 
National Center for Scientific and Technical Research (CNRST-Rabat, Morocco).

\section{REFERENCES}

1. Xiong L, Gao C, Shi YJ, Tao X, Rong J, Liu $\mathrm{KL}$, Peng CT, Wang NY, Lei Q, Zhang YW, Yu LT, Wei YQ. Identification of a new series of benzothiazinone derivatives with excellent antitubercular activity and improved pharmacokinetic profiles. RSC Adv. 2018; 8:11163-76.

2. Armenise $D$, Muraglia $M$, Florio $M A$, De Laurentis N, Rosato A, Carrieri A, Corbo F, Franchini C. 4H-1, 4-Benzothiazine, Dihydro-1, 4benzothiazinones and 2-Amino-5fluorobenzenethiol Derivatives: Design, Synthesis and in vitro Antimicrobial Screening. Arch Pharm. 2012; 345:407-16.

3. Zhang P, Li S, Gao Y, Lu W, Huang K, Ye D, Li X, Chu Y. Novel benzothiazinones (BTOs) as allosteric modulator or substrate competitive inhibitor of glycogen synthase kinase $3 \beta$ (GSK$3 \beta$ ) with cellular activity of promoting glucose uptake. Bioorg Med Chem Lett. 2014; 24:563943.

4. Stößel $A$, Schlenk $M$, Hinz $S$, Küppers $P$, Heer J, Gütschow M, Müller CE. Dual targeting of adenosine $A 2 A$ receptors and monoamine oxidase $\mathrm{B}$ by $4 \mathrm{H}-3$, 1-benzothiazin-4-ones. J Med Chem. 2013; 56:4580-96.

5. Kumar M, Sharma K, Samarth RM, Kumar A. Synthesis and antioxidant activity of quinolinobenzothiazinones. Eur J Med Chem. 2010; 45:4467-72.

6. Borate $\mathrm{HB}$, Maujan SR, Sawargave SP, Chandavarkar MA, Vaiude SR, Joshi VA, Wakharkar RD, Iyer R, Kelkar RG, Chavan SP, Kunte SS. Fluconazole analogues containing $2 \mathrm{H}-$ 1 , 4-benzothiazin-3 (4H)-one or $2 \mathrm{H}-1$, 4benzoxazin-3 $(4 \mathrm{H})$-one moieties, a novel class of anti-Candida agents. Bioorg Med Chem Lett. 2010; 20:722-5.

7. Kamel MM, Ali HI, Anwar MM, Mohamed NA, Soliman AM. Synthesis, antitumor activity and molecular docking study of novel Sulfonamide-Schiff's bases, thiazolidinones, benzothiazinones and their C-nucleoside derivatives. Eur J Med Chem. 2010; 45:572-80.

8. Berwaldt GA, Gouvêa DP, da Silva DS, das Neves AM, Soares MS, Azambuja JH, Spanevello RM, Cunico W. Synthesis and biological evaluation of benzothiazin-4-ones: a possible new class of acetylcholinesterase inhibitors. J Enzyme Inhib Med Chem. 2019; 34:197-203.

9. Ghailane $T$, Balkhmima RA, Ghailane R, Souizi A, Touir R, Touhami ME, Marrakchi K, Komiha N. Experimental and theoretical studies for mild steel corrosion inhibition in $1 \mathrm{M} \mathrm{HCl}$ by two new benzothiazine derivatives. Corros Sci. 2013; 76:317-24.

10. Willardsen JA, Dudley DA, Cody WL, Chi L, McClanahan TB, Mertz TE, Potoczak RE, Narasimhan LS, Holland DR, Rapundalo ST, Edmunds JJ, Design, synthesis, and biological activity of potent and selective inhibitors of blood coagulation factor Xa. J Med Chem. 2004; 47:4089-99.

11. Makarenko SV, Kovalenko KS, Vershinina YS, Berestovitskaya VM. One-pot synthesis of substituted 1,3-benzothiazole and 1,4benzothiazinone from dibromonitroacrylates. Russ J Org Chem. 2014; 50:83-6.

12. Chen D, Wu J, Yang J, Huang L, Xiang Y, Bao W. Cascade syntheses of aza[2,1-b][1,3]benzothiazinone heteropolycyclic compounds from cyclic thiourea catalyzed by $\mathrm{Cu}(\mathrm{I})$. Tetrahedron Lett. 2012; 53:7104-7.

13. Huang W-S, Xu R, Dodd R, Shakespeare WC. Facile synthesis of 1, 4-benzothiazin-3-ones from Cu-catalyzed coupling of 2-iodoanilines and 2-mercaptoacetate. Tetrahedron Lett. 2013; 54:5214-6.

14. Sharifi A, Ansari M, Darabi HR, Abaee MS. Synergistic promoting effect of ball milling and $\mathrm{KF}$-alumina support for the green synthesis of benzothiazinones. Tetrahedron Lett. 2016; 57: 529-32.

15. Ghailane $T$, Saadouni $M$, Boukhris $S$, Habbadi N, Hassikou A, Kerbal A, Garrigues B, Souizi A. Regio-controlled synthesis of 1,4benzothiazinones. Heterocycles. 2011; 83:35763.

16. Bahammou I, Esaady A, Boukhris S, Ghailane R, Habbadi N, Hassikou A, Souizi A. Direct use of mineral fertilizers MAP, DAP, and TSP as heterogeneous catalysts in organic reactions. Mediterr J Chem. 2016; 5:615-23.

17. Merroun $\mathrm{Y}$, Chehab $\mathrm{S}$, Ghailane $\mathrm{T}$, Boukhris S, Ghailane R, Habbadi N, Hassikou A, Lakhrissi B, Souizi A. An effective method to synthesize 2,3-dihydroquinazolin-4(1H)-One using phosphate fertilizers (MAP, DAP and TSP) as green heterogeneous catalysts. J Turk Chem Soc Sect A Chem. 2018; 5:303-16.

18. Zimou O, Malek B, Elhallaoui A, Ghailane T, Ghailane R, Boukhris S, Habbadi N, Hassikou A, Souizi A. Valorization of the Phosphate Fertilizers Catalytic Activity in 1(Benzothiazolylamino) Methy I-2-Naphthol Derivatives Synthesis. Bull Chem React Eng Catal. 2019; 14:238-46. 
